\title{
A comparative study of three rhizospheric bacteria belonging to different genera, co-infecting a leguminous plant
}

\begin{abstract}
Nodules obtained from the roots of fenugreek (Trigonella foenum graecum), a leguminous plant yielded three distinct classes of Nitrogen fixing bacteria. Molecular phylogeny based on 16S rRNA gene sequences showed them to be Enterobacter cloacae (R1), Pantoea dispersa (R10) and Enterobacter ludwigii (R12). The biochemical and morphological characterization of the three bacteria showed many similarities. All were gram negative, rod shaped, giving identical biochemical reactions like Catalase test, MR tests, oxidase test etc. However there were differences in their sensitivity to the abiotic stresses like salinity, tolerance to heavy metal ions and temperature. Sensitivity to antibiotics also showed similar responses. Co-infecting the same plant and occurrence in the same nodules by different genera of bacteria, capable of Nitrogen fixation is a novel phenomenon. The commonly held belief that all Nitrogen fixing mucoid bacteria occurring in nodules of legumes are Rhizobial species is not tenable. Plant growth promoting effects of these bacteria were observed by IAA, siderophore production and inhibition of ethylene biosynthesis by plants by producing the enzyme, ACC Deaminase. The host specificity for one of the bacterium, R1 was shown as only Fenugreek showed nodulation but not mung bean or Bengal Gram seedlings. Nitrogen fixation by the isolated bacteria showed all of these could reduce acetylene to ethylene by gas chromatography.
\end{abstract}

Keywords: nitrogen fixation, nodules, enterobacter species, co-infection, gas chromatography, rhizobial
Volume 3 Issue 3 - 2016

\author{
Pranab Roy, Debdatta Guha, Rajarshi \\ Banerjee, Mukesh Singh \\ Department of Biotechnology, Haldia Institute of Technology, \\ India
}

Correspondence: Pranab Roy, Department of Biotechnology, Haldia Institute of Technology, Haldia, 72 1657, India, Tel 919933037099,

Email pranabroy@rediffmail.com, prpranabroy94@gmail.com

Received: November 08, 2016 | Published: December 28, 2016

\section{Introduction}

Plant-microbe symbiosis has been recognized as the major source of Nitrogen supply to leguminous plants. The root nodules of most of the legumes are associated with Rhizobium sp. and Bradyrhizobium species, which can fix atmospheric Nitrogen gas into ammonia and further to nitrite and nitrate. ${ }^{1,2}$ Recent studies have shown that there are many other genus and species of bacteria, associated with root nodules which can effectively fix Nitrogen, provide the host plant with growth hormones like IAA, reduce ethylene production by synthesizing the enzyme ACC Deaminase and produce siderophores to chelate insoluble metal ions like Fe (III) and make them available to the host plant. ${ }^{3}$ In order to find novel Nitrogen fixing micro-organisms from leguminous root nodules, which are more tolerant to higher temperature and salinity, we chose Fenugreek as the plant hosting the nodulating microbes. In our studies, we isolated and characterized three novel bacteria from the root nodules of Fenugreek (Trigonella foenum). Though belonging to different genera like Enterobacter and Pantoea, these bacteria shared many characters like gram staining, antibiotic sensitivity, IAA production, siderophore production, motility etc; however, there were differences in tolerance to salinity, heavy metal ions and temperature. Pantoea species have been isolated from a wide variety of hosts, both plants and animals; this was classified as Enterobacteriaceae family. ${ }^{4}$ This study revealed that a single leguminous plant root can be nodulated by different types of bacteria, fixing Nitrogen and helping the plant by providing resources.

\section{Materials and methods}

Viable seeds of Fenugreek, Mung bean and Bengal grams were obtained from the local suppliers. All chemicals used in this study are of AR grade, purchased from Himedia and SRL. Acetylene reduction assay for biological nitrogen fixation was carried out at University of Calcutta, West Bengal. All the assays were performed thrice and the standard errors of mean are shown in the graphs.

\section{Isolation and characterization}

Nodules of Fenugreek (Trigonella foenum-graecum) were taken from field grown plants, surface sterilized with $10 \%$ sodium hypochlorite followed by $70 \%$ ethanol wash and several washes with sterile water. Nodules were then crushed and suspended in phosphate buffered saline. Several dilutions were prepared and plated on CRYEMA (Congo Red, yeast extract, mannitol agar) and individual colonies were isolated. Three such colonies, named R1, R10, R12 
were further studied. Biochemical tests, morphology and motility were determined for each isolate. Gram staining was done for the three isolates for their characterization using the standard protocol.

\section{Molecular identification of the three isolates}

Genomic DNA was isolated and tested on $0.8 \%$ agarose gel electrophoresis. The 16S rRNA genes were amplified by using the universal forward primer (27F) and the reverse primer (1492R) under standard PCR conditions. The sequencing of the $1.4 \mathrm{~kb}$ amplicons were carried out by automated DNA sequence at Chromous Biotech Pvt. Ltd., Bangalore, India. The sequences were deposited at NCBI with the accession numbers, KX68756 (R1), KX687557 (R10), KX687554 (R12). Molecular phylogenetic analysis was done with MEGA 7.1 software.

\section{Bacterial growth curve}

24hour grown fresh cultures of the three isolates were taken and inoculated of fresh LB broth and the bacterial growth pattern was studied at $30^{\circ} \mathrm{C}$ spectrophotometrically from 0 to 14 hours by taking absorbance at $650 \mathrm{~nm}$ at every one hour. Graphs were plotted with bacterial growth against time intervals in hours.

\section{Root infection test of the RI isolate}

Plant infection and root nodule formation confirm the host specificity of a particular bacterium. This study also provides the basis to screen the efficiency of a bacterial strain for nodulation and nitrogen fixation. Viable seeds of Fenugreek (Trigonella foenumgraecum) (M), Mung bean (MB) and Bengal gram (BG) were obtained from local suppliers. Seeds were surface sterilized with $10 \%$ sodium hypochlorite followed by $70 \%$ ethanol wash and several washes with sterile water. Seeds were soaked in water overnight for germination. Seeds were placed in Murashig Skoog (MS) medium in choir bed in different sets, Set-I contained MS medium without Nitrogen $(\mathrm{N})$ source and with the R1 inoculum, Set-II contained MS medium with $\mathrm{N}$ source but was without the inoculum and Set-III had both MS medium with $\mathrm{N}$ source and the bacterial inoculums. Seedlings were kept in Plant chamber maintaining 16hrs light and 8hrsdarkness for about 28days. The roots of the seedlings were observed and studied after 15 th day and 28 th day under microscope.

\section{Protein estimation from the root extracts of the seedings}

Protein was estimated from the root extracts by Bradford. ${ }^{5}$ Root extracts were crushed and the extracts were suspended in phosphate buffer saline. A protein standard curve was prepared with BSA $(1 \mathrm{mg}$ $\mathrm{ml})$. Extracts were then incubated for 5-15mins with the Bradford reagent until the blue colour develops and then the absorbance was recorded at $595 \mathrm{~nm}$.

\section{Carbohydrate esitmation from the root extracts of the seedlings :}

Carbohydrate was estimated from the root extracts by the phenol sulphuric acid method. ${ }^{6}$

\section{Salinity tolerance}

Salinity tolerance of the three isolates were studied in LB (LuriaBertani) medium with different concentrations of $\mathrm{NaCl}(0$ to $1 \mathrm{M})$. 48hours cultures were taken and inoculated in LB medium with varying salt concentrations and incubated at $30^{\circ} \mathrm{C}$ for 24 hours in shaker and absorbance was taken at $600 \mathrm{~nm}^{7}$

\section{Temperature tolerance}

Temperature tolerance of the three isolates were studied by plating on LB agar and incubating for 24 and 48 hours at different temperatures $30^{\circ} \mathrm{C}, 37^{\circ} \mathrm{C}, 42^{\circ} \mathrm{C}$. Colonies were observed to find out their tolerance to different temperatures.

\section{Nitrogen fixation}

All the three isolates were capable of growing in Nitrogen free media like Jensen's agar and YEM agar, indicating their ability to fix atmospheric Nitrogen. The three isolates were tested by the Acetylene reduction assay where acetylene is reduced to ethylene by the enzyme Nitrogenase, responsible for nitrogen fixation. Ethylene peaks measured by Gas chromatography were quantified for the enzyme activities. $^{8}$

\section{Antibiotic sensitivity of the three isolates}

Antibiotic sensitivity was observed by spreading the three purified cultures on LB plates on which different antibiotic containing filter discs were placed and incubated overnight at $30^{\circ} \mathrm{C}$. The antibiotics used in this study are: Ampicillin $(25 \mu \mathrm{g} /$ disc $)$, Gentamycin $(10 \mu \mathrm{g} / \mathrm{disc})$, Trimethoprim $(30 \mu \mathrm{g} / \mathrm{disc}), \quad$ Tetracycline $(30 \mu \mathrm{g} / \mathrm{disc})$, Streptomycin $(10 \mu \mathrm{g} / \mathrm{disc})$, Vancomycin $(30 \mu \mathrm{g} / \mathrm{disc})$, Doxycycline $(30 \mu \mathrm{g} / \mathrm{disc})$, Cloxacillin $(10 \mu \mathrm{g} / \mathrm{disc})$ The zone of inhibition around the filter discs (from Himedia) were measured in diameter. The sensitivity and resistivity of the three isolates with each antibiotic were observed.

\section{Heavy metals tolerance}

Heavy metal ions tolerance was studied by making stock solutions of $10 \mathrm{mM}$ each and then broth cultures of the three isolates were inoculated on fresh LB medium supplemented with metal ions $(\mathrm{Pb}, \mathrm{Cr}, \mathrm{Hg}, \mathrm{Co})$ of increasing concentrations $(83,166,250,330,410,500 \mu \mathrm{M})$ followed by incubation at $30^{\circ} \mathrm{C}$ overnight. The absorbance was recorded at $600 \mathrm{~nm}^{9}$

\section{Detection of plant growth hormones by the three isolates}

\section{Indole acetic acid production}

Indole-3-acetic acid (IAA) is a phytohormone, which is essential for the growth and development of plants. It is known to increases in cell elongation and cell division and differentiation responses in plants. ${ }^{10,11}$ The capacity to synthesize IAA is widespread among soiland plant associated bacteria. It has been estimated that most of the bacteria isolated from the rhizosphere can produce the plant growth regulator IAA. Tryptophan is the precursor of IAA. ${ }^{12}$ The colorimetric technique proposed by Gordon et al. ${ }^{13}$ the three isolates were grown LB liquid medium with tryptophan $(1 \mathrm{mg} / \mathrm{mL})$ at $30^{\circ} \mathrm{C}$ with shaking for three days. The supernatant of the culture was recovered after centrifuged. Thereafter, supernatant was taken in a test tube and $2 \mathrm{~mL}$ IAA reagent $(1 \mathrm{~mL}$ of $0.5 \mathrm{M} \mathrm{FeCl} 3$ was mixed in $50 \mathrm{~mL}$ of $35 \%$ $\mathrm{HClO} 4)$ was added. After incubation for $20 \mathrm{~min}$ at room temperature, the optical density of the samples was recorded at $550 \mathrm{~nm}$ with respect to blank medium as the control.

\section{ACC Deaminase assay}

The ACC Deaminase activities of the isolates were qualitatively measured in agar plates following the method of Glick et al. ${ }^{14}$ The isolates were inoculated on solid medium plates containing carbon and nitrogen free DF salt minimal medium ${ }^{15}$ supplemented with 
ACC where ACC act as sole carbon and nitrogen source. The plates were incubated at $30^{\circ} \mathrm{C}$ for 3 days and observed for colony formation. The colonies formed in DF medium supplemented with ACC were considered positive for ACC Deaminase activity. DF salt minimal medium without ACC supplement was used as control. The quantitative estimation of ACC Deaminase activity was assayed according to a modified method of Honma et al., ${ }^{3}$ which measures the amount of $\alpha$-ketobutyrate produced when the ACC Deaminase cleaves ACC. The amount of $\alpha$-ketobutyrate was quantified spectrophotometrically at $550 \mathrm{~nm}$.

\section{Detection of siderophore production}

Assay for siderophore production by the three isolates was carried out by spot inoculating purified cultures on Chrome azurol $\mathrm{S}$ agar plates and incubated at $30^{\circ} \mathrm{C}$ for 3-4days. ${ }^{16}$

\section{Results and discussion}

\section{Molecular identification and characterization}

Bacterial isolates R1, R10 and R12 colonies were all mucoid with exopolysaccharide. 16S rRNA sequencing identified the three isolates as, isolate R1 to be Enterobacter cloacae, ${ }^{17}$ isolate R10 to be Pantoea dispersa and isolate R12 to be Enterobacter ludwigii (Table 1). The phylogenetic trees for the three isolates generated by the software MEGA 7.1 were obtained from the sequence data of the $16 \mathrm{~S}$ rDNAs as follows: (Figure 1A-1C).

Table I Molecular identification and characterization

\begin{tabular}{llll}
\hline Sample code & Source & Accession numbers & Identified organisms \\
\hline RI & Root nodules & KX687556 & Enterobacter cloacae \\
RI0 & Root nodules & KX687557 & Pantoea dispersa \\
RI2 & Root nodules & KX687554 & Enterobacter ludwigii \\
AI & Rhizospheric soil & KX687553 & Pseudomonas sp \\
PI & Rhizospheric soil & KX687555 & Pseudomonas sp \\
\hline
\end{tabular}
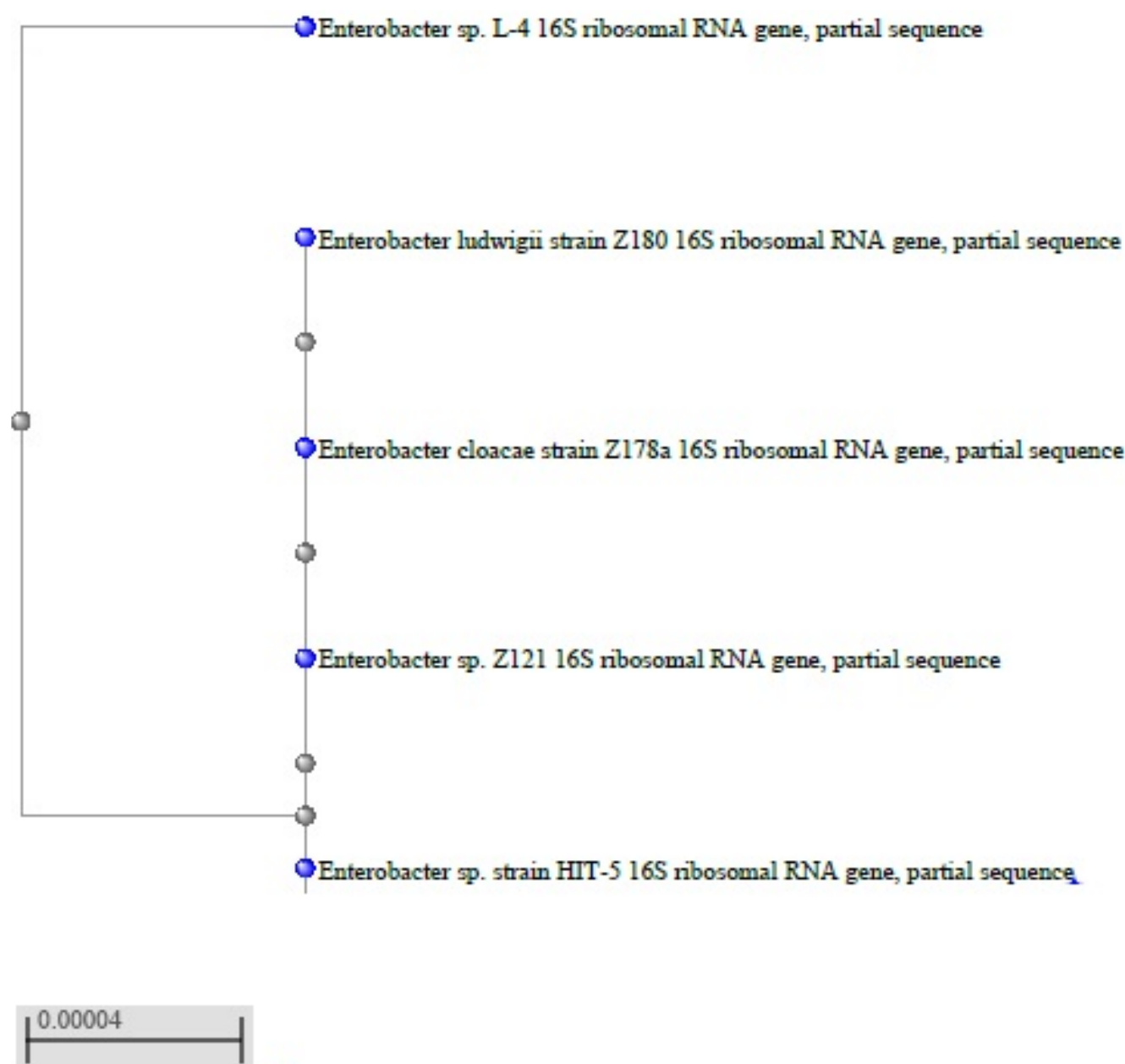

IA: HIT $5=$ RI2 Isolate. 


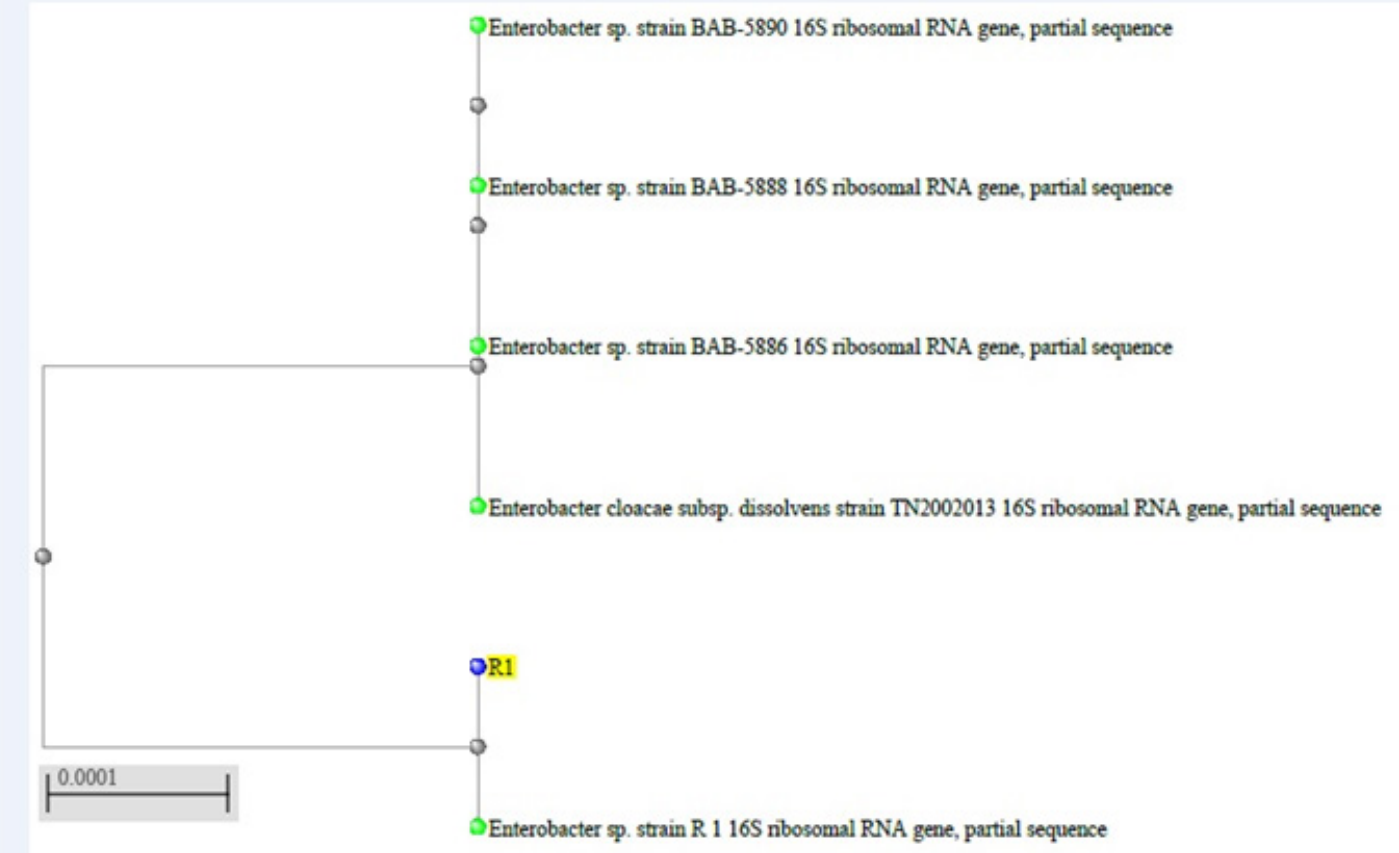

IB: RI Isolate.

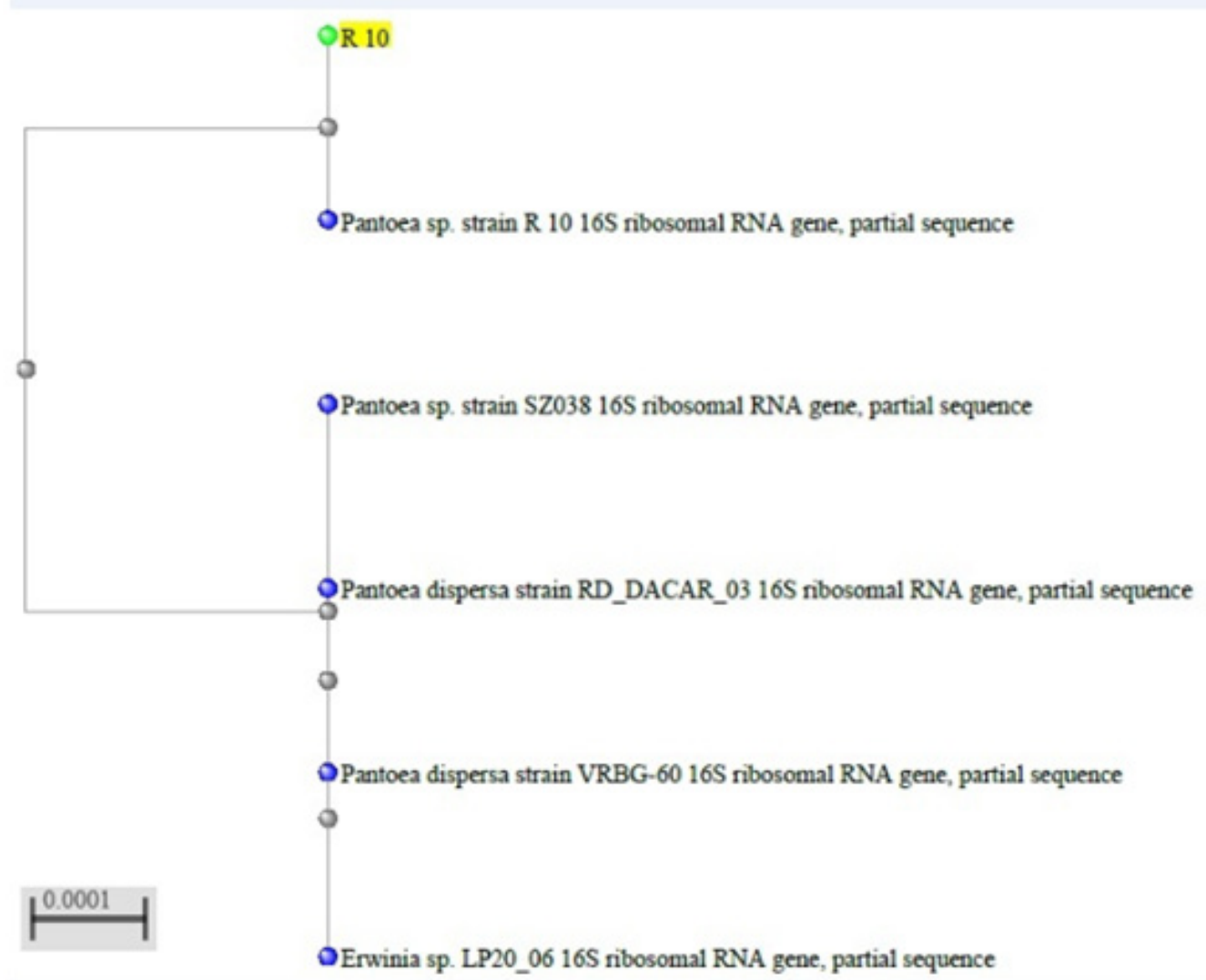

IC: R 10 Isolate

Figure I: The phylogenetic trees for the three isolates generated by the software MEGA 7.I were obtained from the sequence data of the I6S rDNAs 


\section{Gram staining}

All the three isolates were found gram negative short rods under 100X magnification (Figure 2).

\section{Biochemical tests}

The routine biochemical tests for each of the three isolates were carried out (Table 2). Many of the tests gave identical results except VP test where R10 isolate showed positive result where the other two were negative and in Indole test R12 isolate showed positive result where the other two were negative. TSI agar test showed R10 isolate to be different from R1 and R12 isolates. Since both R1 and R12 were Enterobacter species, it showed similar reactions for metabolizing different sugars, but R10, a Pantoea specie was different.

Table 2 The routine biochemical tests for each of the three isolates were carried out

\begin{tabular}{llll}
\hline Test & RI & $\mathbf{R I 0}$ & $\mathbf{R I 2}$ \\
\hline I.Catalase & - & - & - \\
2.Citrate & ++ & ++ & ++ \\
$\begin{array}{l}\text { 3.Oxidase } \\
\text { 4.Indole }\end{array}$ & ++ & ++ & ++ \\
5.MR & - & - & ++ \\
6.VP & - & - & - \\
7.Gelatinase & ++ & - & - \\
8. Growth on Glucose & - & - & ++ \\
peptone agar & ++ & ++ & +++ \\
9.Motility & +++ & +++ & Acid formation with no gas formation \\
& Acid formation with no gas & Acid formation with gas & and all the three sugars were \\
I0.TSI Agar test & formation and all the three & formation and only glucose & fermented \\
& sugars were fermented & fermented & \\
\hline
\end{tabular}

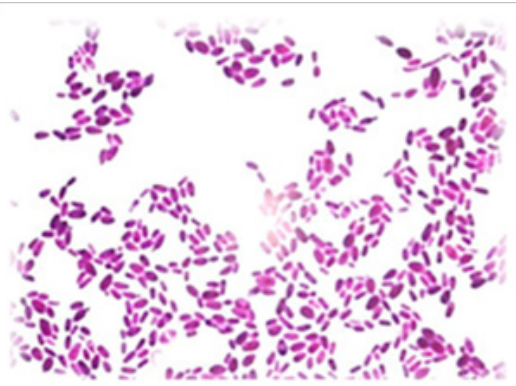

2A, R1 Isolate

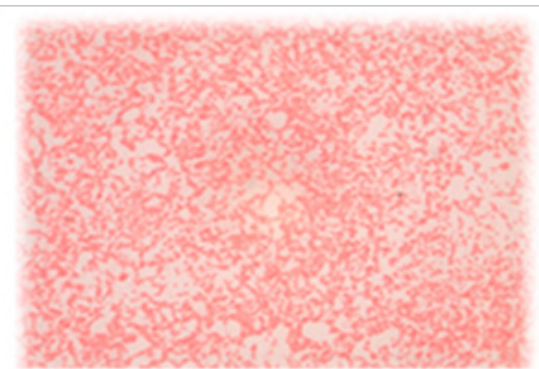

2B, R12 Isolate.

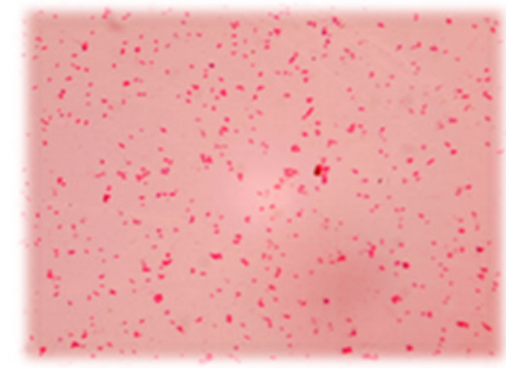

2C, R10 Isolate.

Figure 2 All the three isolates were found gram negative short rods under 100X magnification.

\section{Root infection test of the $\mathbf{R} \mathbf{I}$ isolate}

Figure 3 shows the root infection of Fenugreek seedling. Only Fenugreek showed nodulation after 28days with R1 inoculation
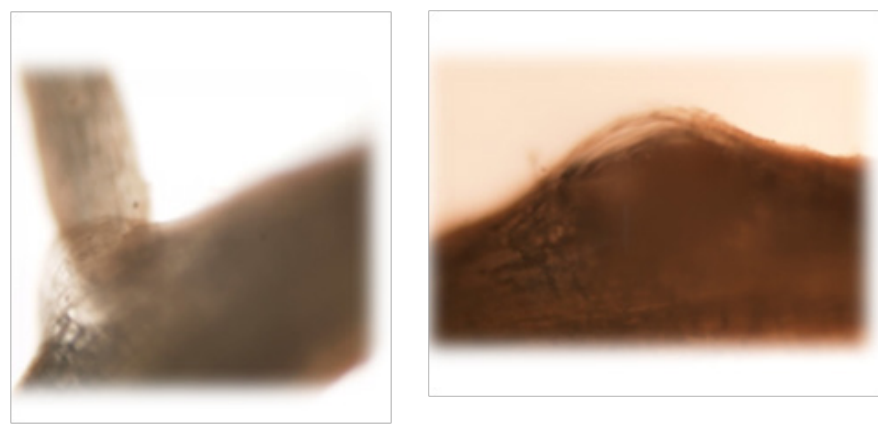

showing host specificity. Only Fenugreek roots were nodulated by R1 but not mung bean or Bengal gram. Figure 4 shows the initiation of the nodule formation in Fenugreek seedling after 15days of infection with $\mathrm{R} 1$ isolate.
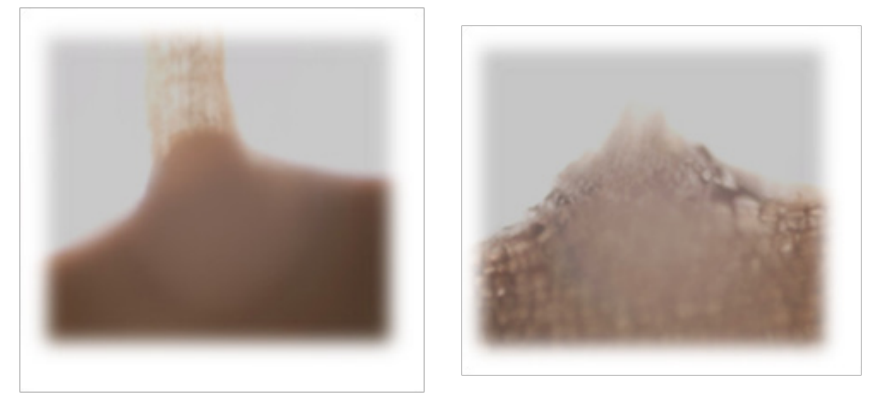

Figure 3 The root infection of Fenugreek seedling. 

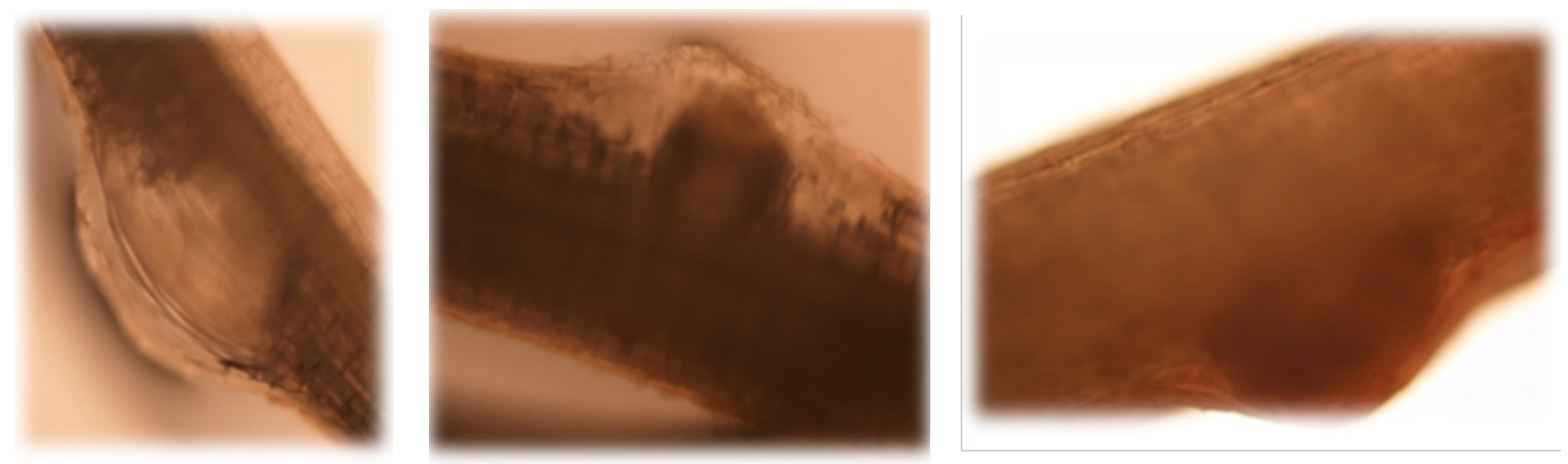

Figure 4 The initiation of the nodule formation in Fenugreek seedling after I 5 days of infection with $\mathrm{RI}$ isolate.

\section{Protein and carbohydrate estimation from the root extracts}

(Figure 5A \& Figure 5B) for carbohydrate and protein estimation with seedlings of Fenugreek, Mung bean and Bengal gram. Set III which had N source and inoculated with R1 had the highest levels of protein and carbohydrate for all the three seedlings.

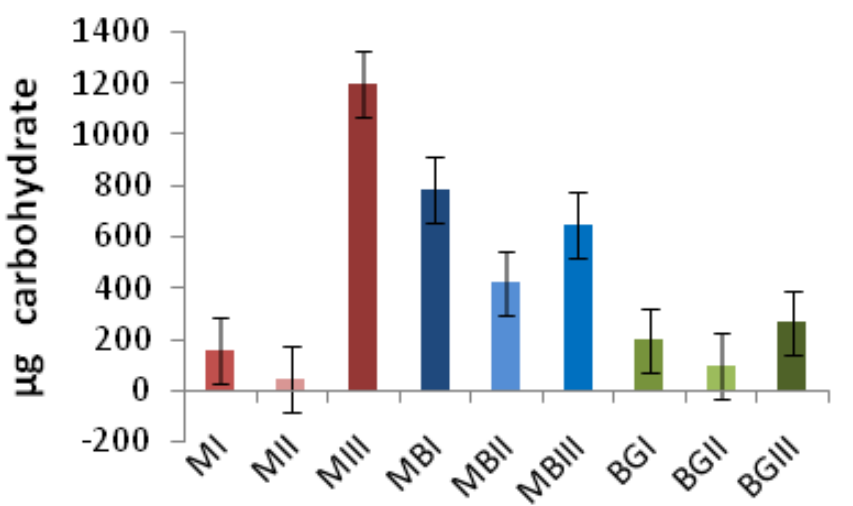

$5 \mathbf{A}$

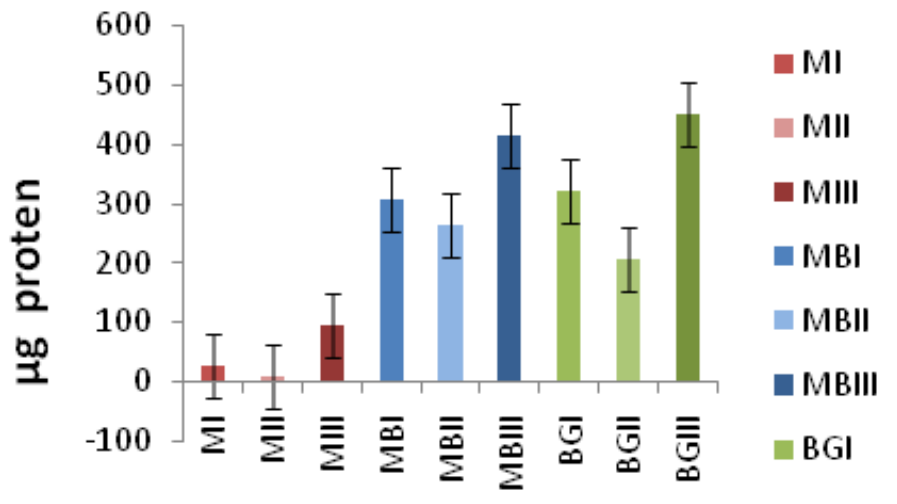

5B

Figure 5 Carbohydrate and protein estimation with seedlings of Fenugreek, Mung bean and Bengal gram.

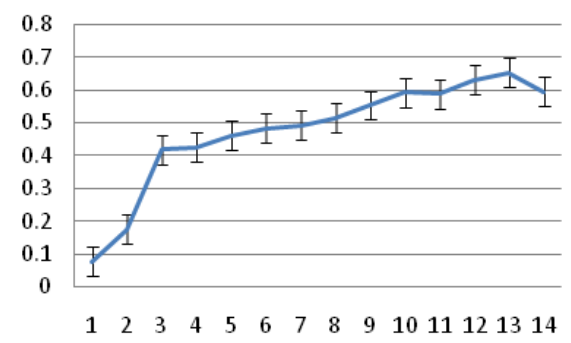

6A: RI

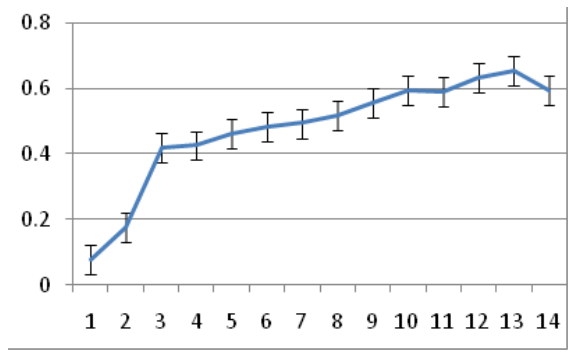

6B: RI0

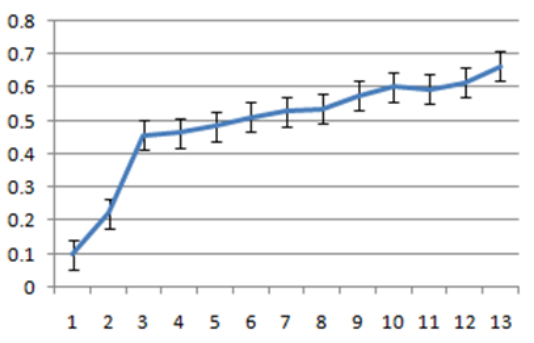

6c: $R / 2$

Figure $\mathbf{6}$ The growth kinetics of the three isolates, where the absorbances of the cultures at different time points after inoculation are plotted against time in hours.

\section{Salinity tolerance}

Figures $7 \mathrm{~A}-7 \mathrm{C}$ shows the bacterial growth in different salt concentration and their tolerance towards salt stress. Isolate R12 (Figure 7C) shows $50 \%$ inhibition at $500 \mathrm{mM} \mathrm{NaCl}$ salt concentration and proves to be highly salt tolerant whereas isolate R10 (7b) and isolate $\mathrm{R} 1(7 \mathrm{a})$ shows $50 \%$ inhibition at $50 \mathrm{mM}$ and $350 \mathrm{mM} \mathrm{NaCl}$ salt concentrations respectively. Thus the salinity tolerances of the three nodule associated bacteria were quite different. 

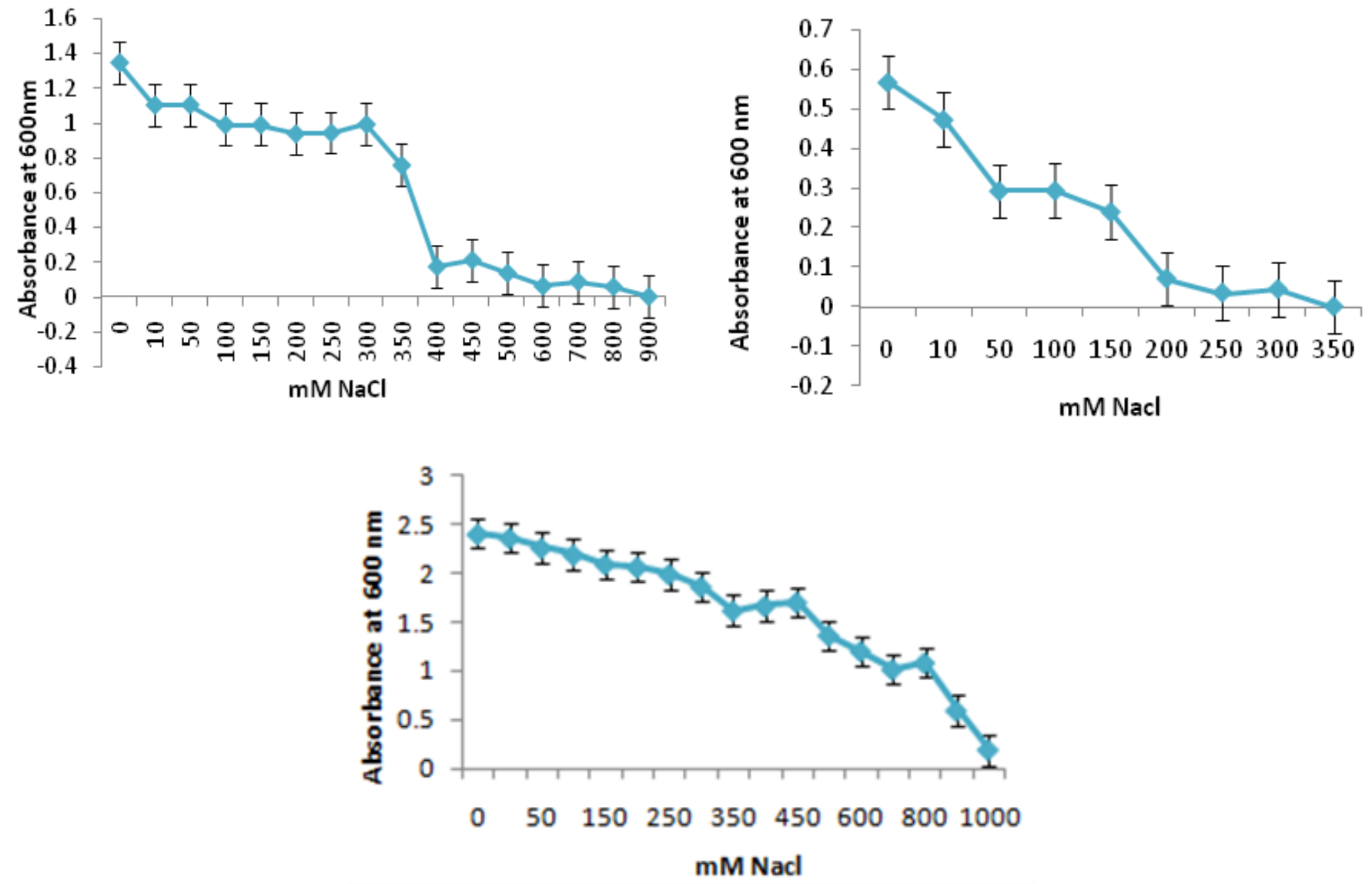

7A. $\mathbf{R I}$ Isolate Isolate $\mathrm{RI}$ shows $50 \%$ inhibition at $350 \mathrm{mM} \mathrm{NaCl}$ salt concentrations.

7B. RIO isolate Isolate RIO shows $50 \%$ inhibition at $50 \mathrm{mM} \mathrm{NaCl}$ salt concentrations.

7C. $R / 2$ isolate Isolate RI2 shows $50 \%$ inhibition at $500 \mathrm{mM} \mathrm{NaCl}$ salt concentration and proves to be highly salt tolerant.

\section{Temperature tolerance}

Table 3 shows isolate R1 and R12 had optimum growth at $37^{\circ} \mathrm{C}$ whereas isolate $\mathrm{R} 10$ grew maximally at $30^{\circ} \mathrm{C}$._Temperature tolerance of the three isolates were compared in LB medium. Both the Enterobacter species, R1 and R12 showed maximum growth at $37^{\circ} \mathrm{C}$ whereas R10 (Pantoea) which is reported to be cold tolerant had better growth at $30^{\circ} \mathrm{C} . .^{18}$

Table 3 Shows isolate RI and RI2 had optimum growth at $37^{\circ} \mathrm{C}$ whereas isolate $\mathrm{R} / 0$ grew maximally at $30^{\circ} \mathrm{C}$

\begin{tabular}{llll}
\hline \multirow{2}{*}{ Bacterial species } & \multicolumn{3}{l}{ Temperature } \\
\cline { 2 - 4 } & $30^{\circ} \mathbf{C}$ & $37^{\circ} \mathbf{C}$ & $\mathbf{4 2}{ }^{\circ} \mathbf{C}$ \\
\hline I. Enterobacter cloacae $(R I)$ & +++ & +++++ & ++ \\
2. Pantoea dispersa (R/O) & & & +++++ \\
3. Enterobacter ludwigii $(R / 2)$ & ++ & + \\
\hline
\end{tabular}

\section{Nitrogen fixation}

Acetylene Reduction Assay was carried out with the three isolated colonies on agar slants using Gas Chromatography. R12 showed the highest activity followed by $\mathrm{R} 1$ and $\mathrm{R} 10$ respectively as calculated by the areas under the peaks of ethylene in the chromatograms (data not shown).

\section{Metal ion toxicity}

The three strains R1, R10 and R12, grown in LB medium with different concentrations of metal ions $\mathrm{Pb}$ (II), $\mathrm{Co}$ (II), $\mathrm{Cr}$ (VI), $\mathrm{Hg}$ (II) showed that $\mathrm{R} 1$ strain was tolerant to $\mathrm{Pb}$ and $\mathrm{Co}$ whereas it was sensitive to $\mathrm{Cr}$ and $\mathrm{Hg}$ ions at $83 \mu \mathrm{M}$. R10 and R12 strains were sensitive to $\mathrm{Pb}$ but more resistant to $\mathrm{Co}, \mathrm{Cr}$ and $\mathrm{Hg}$ at $83 \mu \mathrm{M}$ concentration. 
a. Lead $(\mathrm{Pb})$ Tolerance: Chart 1

b. Cobalt Tolerance (Co): Chart 2

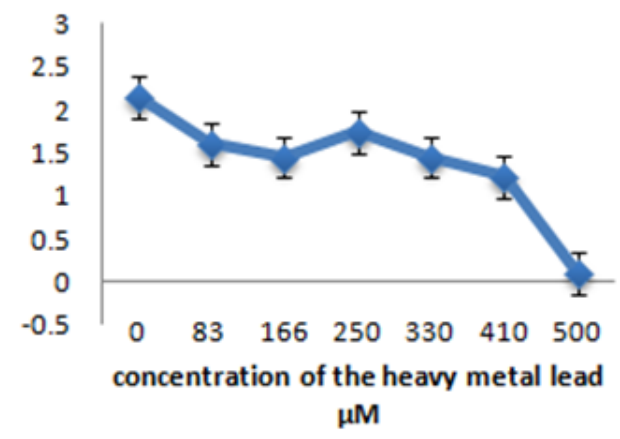

A: RI Isolate: (Enterobacter cloacae) c. Chromium Tolerance (Cr): Chart 3

d. Mercury Tolerance $(\mathrm{Hg})$ : Chart 4

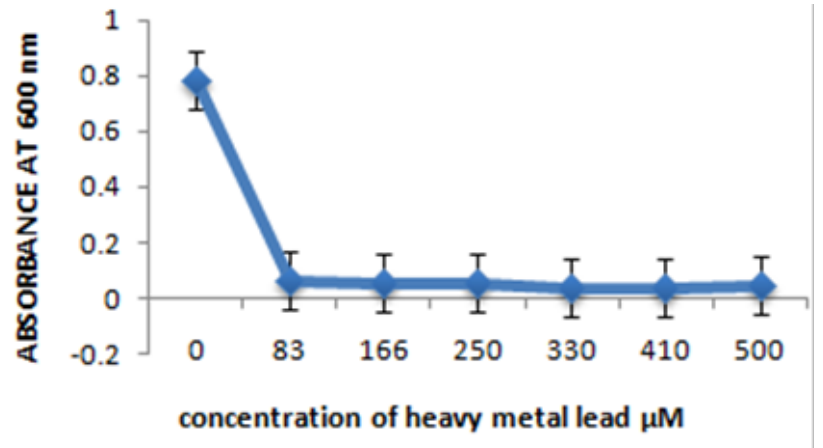

B: RIO Isolate: (Pantoea dispersa)

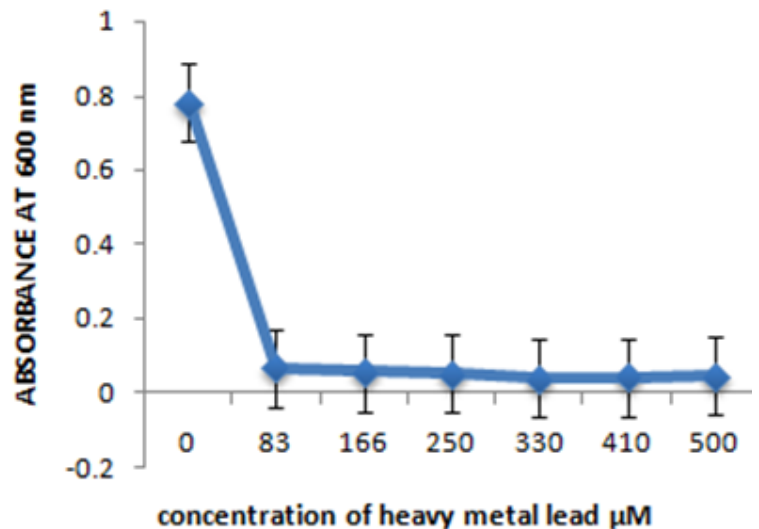

C: RI2 Isolate: (Enterobacter ludwigii)

Chart I Lead $(\mathrm{Pb})$ Tolerance

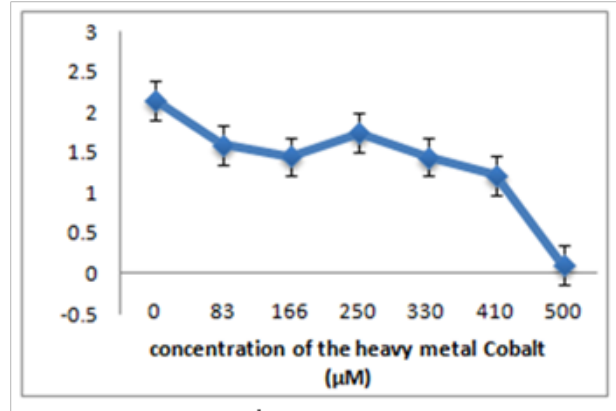

A. R1 Isolate, (Enterobacterfcloacae)

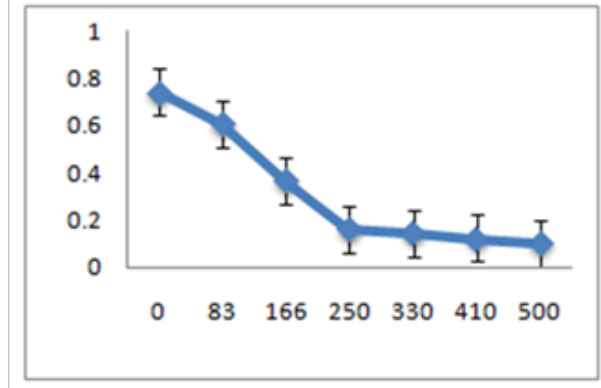

B. R10 Isolate, (Pantoea dispersa)

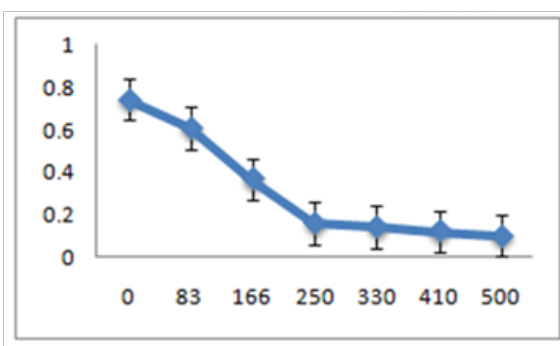

C. R12 Isolate, (Enterobacter ludwigii)

Chart 2 Cobalt tolerance (Co) 


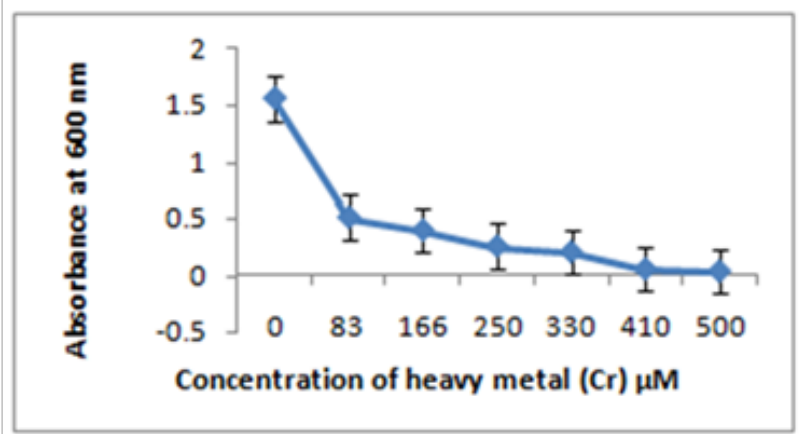

A. R1 Isolate.

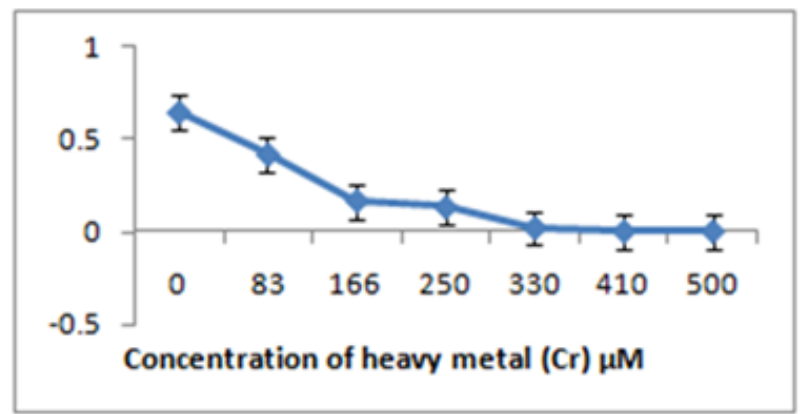

B. R10 isolate.

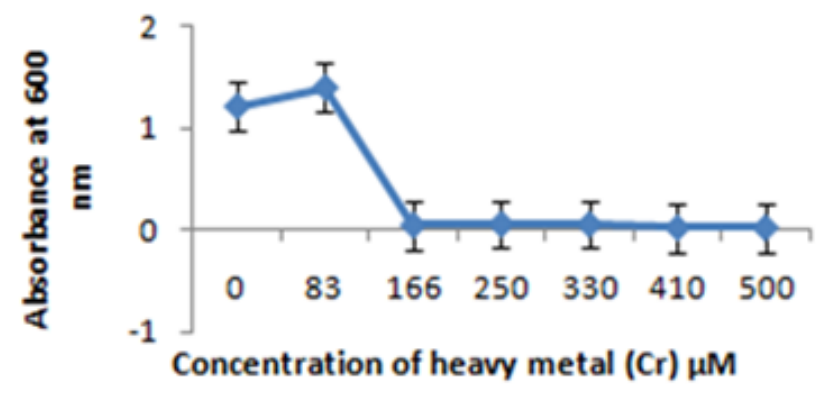

\section{R12 isolate.}

Chart 3 Chromium tolerance $(\mathrm{Cr})$

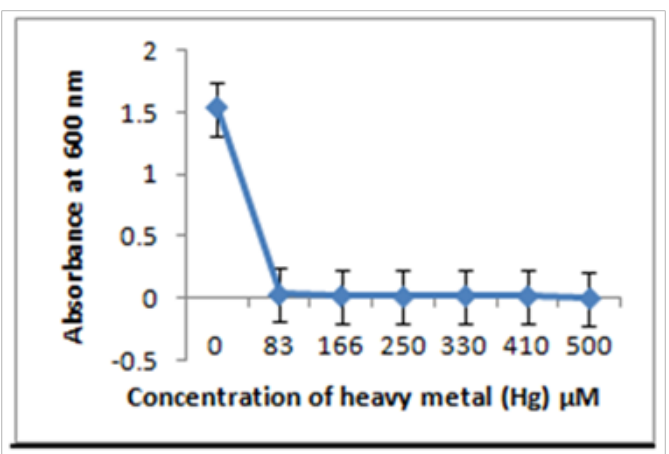

A.R1 Isolate.

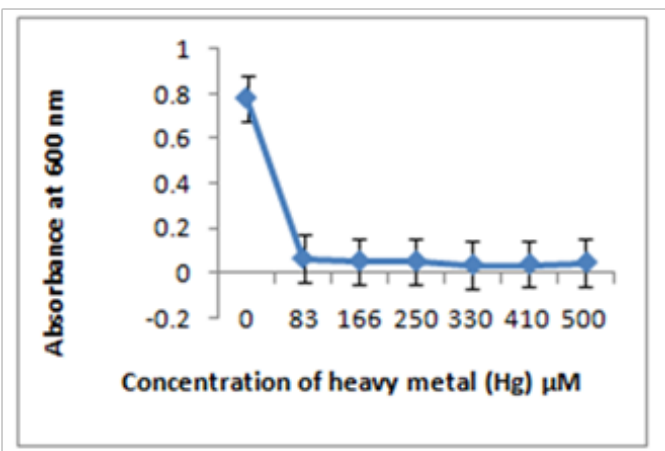

B. R10 Isolate

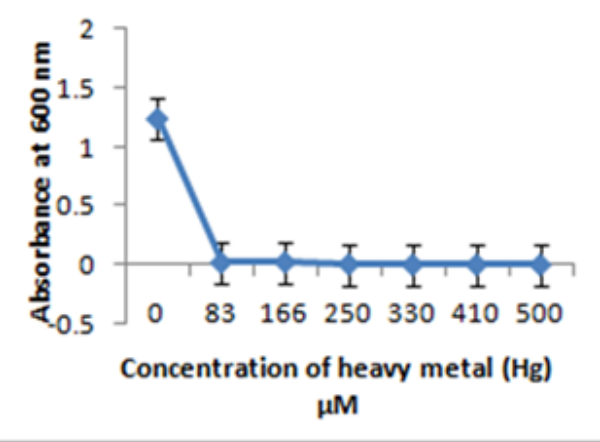

C. R12 Isolate

Chart 4 Mercury tolerance $(\mathrm{Hg})$ 


\section{Antibiotic sensitivity}

Isolates $\mathrm{R} 1, \mathrm{R} 10$ and $\mathrm{R} 12$ showed identical results on antibiotic discs when placed on solid media. R1, R10 and R12 were found to be sensitive to Ampicillin, Vancomycin and Cloxacllin antibiotics whereas showed resistance to all the other antibiotics (Table 4).

Table 4 Antibiotic sensitivity

\begin{tabular}{llll}
\hline Antibiotics & RI & RI0 & RI2 \\
\hline Ampicillin & Sensitive & Sensitive & Sensitive \\
Gentamycin & Resistant & Resistant & Resistant \\
Trimethoprim & Resistant & Resistant & Resistant \\
Tetracycline & Resistant & Resistant & Resistant \\
Streptomycin & Resistant & Resistant & Resistant \\
Vancomycin & Sensitive & Sensitive & Sensitive \\
Cloxacillin & Sensitive & Sensitive & \\
\hline
\end{tabular}

\section{Indole acetic acid production}

The three isolated bacteria $\mathrm{R} 1, \mathrm{R} 10$ and $\mathrm{R} 12$ were able to produce indole acetic acid when recorded spectrophotometrically whereas a negative control E. coli did not produce IAA (Table 5).

Table $\mathbf{5}$ Indole acetic acid production

\begin{tabular}{lll}
\hline $\mathbf{R} \mathbf{I}$ & $\mathbf{R} \mathbf{0}$ & $\mathbf{R} \mathbf{2}$ \\
\hline++ & +++++++ & ++++
\end{tabular}

\section{ACC deaminase activity}

The three isolates were found to have ACC Deaminase activity when plated on DF minimal media supplemented with ACC as the sole carbon and nitrogen source. Colonies appeared on the plates; also colorimetrically it had been shown to grow in DF medium whereas a negative control showed no growth in this minimal medium. ACC Deaminase is the enzyme which reduces the biosynthesis of ethylene, a plant hormone inhibiting plant growth. Thus these bacteria act as plant growth promoters (Table 6).

Table 6 ACC deaminase activity

\begin{tabular}{lll}
\hline $\mathbf{R}$ I & RI0 & RI2 \\
\hline+++ & +++++ & +++++++ \\
\hline
\end{tabular}

\section{Detection of siderophore production by the three isolates}

The three isolates showed growth on Chrome Azurol S agar plates forming orange halo zone around the colonies against the blue background. Half of the plates were streaked with individual bacterium and the other half was spotted with the same. This indicates that the three isolates produced siderophores which can chelate Fe(III) from insoluble to soluble form, making it available to plants (Figure 8).

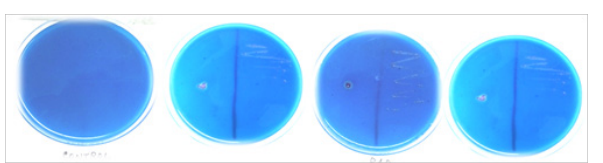

Figure 8 Detection of siderophore production by the three isolates.

Control, RI, RIO, RI2

\section{Conclusion}

Amongst the Bio fertilizers used commercially Nitrogen fixing microbes and Phosphate solubilizing bacteria are the most common. The performance of these bacteria under unfavorable climatic conditions are poor. High temperature, salinity and occurrence of heavy metal ions inhibit the activities of these micro-organisms. In order to study the microbes associated with a leguminous plant root, we isolated three novel bacteria from Fenugreek root nodules. The biochemical and morphological characterization followed by molecular identification of the three isolates were carried out. These were found to be R1 (Enterobacter cloacae), R10 (Pantoea dispersa) and R12 (Enterobacter ludwigii) respectively. Antibiotics sensitivity and plant growth promoting activities were found to be similar in all three.

\section{Acknowledgements}

None.

\section{Conflict of interest}

Author declares that there is no conflict of interest.

\section{References}

1. Arnold W, Becker A, Keller M, et al. The role of Rhizobium meliloti surface polysaccharides in the infection of Medicago sativa nodules. Endocytobiosis Cell Res. 1994;10:17-28.

2. Shahzad F, Shafee M, Abbas F, et al. Isolation and biochemical characterization of Rhizobium meliloti from root nodules of alfalfa (Medicago sativa). The Journal of Animal and Plant Science. 2012;22(2):522-524.

3. Honma M, Shimomura T. Metabolism of 1-aminocyclopropane-1 carboxylic acid. Agric Biol Chem. 1978;42:1825-1831.

4. Walterson AM, Stavrinides J. Pantoea: insights into a highly versatile and diverse genus within the Enterobacteriaceae. FEMS Microbiol Rev. 2015;39(6):968-984.

5. Bradford MM. A rapid and sensitive for the quantitation of microgram quantitites of protein utilizing the principle of protein-dye binding. Analytical Biochemistry. 1976;72:248-254.

6. Dubois M, Gilles KA, Hmillton JK, et al. Colorimetric method for determination of sugars and related substances. Anal Chem. 1956;28(3):350-356.

7. Singh RP. Isolation and characterization of multifarious plant growth promoting bacteria Enterobacter ludwigii PGP 19 isolated from pearl millet. International Journal of Science and Research (IJSR). 2013;6(14):2319-7064.

8. Hardy RWF, Holsten RD, Jackson EK, et al. The acetylene ethylene assay for N2 fixation: laboratory and field evaluation. Plant Physiol. 1968;43(8):1185-1207.

9. Nies DH. Microbial heavy metal resistance. Appl Microbiol Biotechnol. 1999;51(6):730-750.

10. Cleland RE. Auxin and cell elongation. In: Davies PJ, editor. Plant Hormones and their role in plant growth and development. Dordrecht, the Netherlands: Kluwer Academic Publishers; 1990. p. 132-148.

11. Hagen G. The control of gene expression by auxin. In: Davies PJ, editor. Plant hormones and their role in plant growth and development. Dordrecht: Kluwer Academic Publishers; 1990. p. 149-163.

12. Antoun H, Kloepper JW. Plant growth promoting rhizobacteria. In: Brenner S, Miller JF, editors. Encyclopedia of Genetics. New York: Academic Press; 2001. p. 1477-1480. 
13. Gordon SA, Weber RP. Colorimetric estimation of indole-acetic acid Plant Physiology. 1951;26(1):192-195.

14. Glick BR, Karaturovic D, Newell P. A novel procedure for rapid isolation of plant growth promoting rhizobacteria. Can J Microbiol. 1995;41(6):533-536.

15. Dworkin M, Foster JW. Experiments with some microorganisms which utilize ethane and hydrogen. J Bacteriol. 1958;75(5):592-603.
16. Schwyn B, Neilands JB. Universal chemical assay for the detection \& determination of siderophores. Anal Biochem. 1987;160(1):47-56.

17. Shrivastava UP. Molecular characterization of rhizobacteria associated with the rice plant of Indo-Nepal border. School of Biotechnology, Banaras Hindu University, Varanasi, India; 2009.

18. Paul D, Lade H. Plant growth promoting rhizobacteria to improve crop growth in saline soils: A Review, Agron. Sustain Dev. 2014;34:737-752. 